\title{
Effects of Neck-Specific Exercises Compared to Waiting List for Individuals With Chronic Whiplash-Associated Disorders: A Prospective, Randomized Controlled Study
}

Anneli Peolsson, Maria Landén Ludvigsson, Ann-Marie Tigerfors and Gunnel Peterson

\section{Linköping University Post Print}

\section{Tweet}

N.B.: When citing this work, cite the original article.

Original Publication:

Anneli Peolsson, Maria Landén Ludvigsson, Ann-Marie Tigerfors and Gunnel Peterson, Effects of Neck-Specific Exercises Compared to Waiting List for Individuals With Chronic Whiplash-Associated Disorders: A Prospective, Randomized Controlled Study, 2016, Archives of Physical Medicine and Rehabilitation, (97), 2, 189-195.

http://dx.doi.org/10.1016/j.apmr.2015.10.087

Copyright: WB Saunders

http://www.elsevier.com/

Postprint available at: Linköping University Electronic Press

http://urn.kb.se/resolve?urn=urn:nbn:se:liu:diva-125676 
Effects of neck-specific exercises compared to waiting list for individuals with chronic whiplash associated disorders: a prospective randomized controlled study 


\begin{abstract}
Objective: To determine, whether 3-months of neck-specific exercises could benefit individuals with chronic whiplash-associated disorders (WAD) who were on a waiting list for treatment.
\end{abstract}

Design: A prospective, randomized controlled study

Setting: Primary health care

Participants: 41 individuals (31 women, 10 men; mean age=38 y, SD=11.2) with chronic (6 to 36 months) WAD, grades 2 and 3, were analyzed.

Interventions: Patients were randomized to neck-specific exercises (NSE) or no treatment for 3 months.

Main outcome measures: Neck-specific disability (Neck Disability Index; NDI), neck pain (Visual Analogue Scale), general pain-related disability (Pain Disability Index; PDI), selfperceived performance ability (the Self-Efficacy Scale; SES), and health-related quality of life (EuroQol five dimensions; EQ-5D) were measured.

Results: NSE significantly improved the NDI, SES, and EQ5D compared to waiting list $(<0.01)$. There was significant improvement $(\mathrm{p}<0.0001)$ over time in all outcomes for NSE, and, apart from the PDI, significant worsening ( $\mathrm{p}=0.002$ to 0.0002 ) over time for the untreated group.

Conclusions: NSE were more beneficial than no intervention while on a waiting list for individuals with chronic WAD.

Key words: whiplash, spine, chronic, exercise, randomized 


\section{Introduction}

Whiplash-associated disorder (WAD) are common, with an annual incidence of up to 600 per 100000 individuals [1, 2]. WAD is caused by an indirect trauma to the neck, often due to a motor vehicle accident. Among individual with a chronic (duration >6 months) WAD, about $50 \%$ experience continuous symptoms interfering with their daily life [3, 4]. In addition, individuals with WAD commonly report a reduced extent of one's belief in one's own ability to complete tasks and reduced health-related quality of life [1]. A WAD diagnosis is based on the medical history and a physical examination [5]. To date, there is no consensus regarding the multi-factorial mechanisms underlying prolonged WAD symptoms. However, individuals with more severe or chronic problems exhibit certain morphological changes, with fatty infiltration in the multifidus muscle [6]; altered neck muscle behavior [7, 8]; and decreased muscle function [9] compared to healthy individuals. It is therefore reasonable to assume that a treatment targeting neck muscles may improve symptoms and quality of life in individuals with WAD.

There is no consensus on the best treatment for chronic WAD [10,11], but recommendations include to remain active and perform some kind of exercises [1, 11, 12]. Randomized trials that investigated exercise in chronic WAD has reported conflicting results. Four large randomized controlled trials were identified in the literature [13-16]. Stewart et al. [13] compared a 6-week general exercise and cognitive behavioral program to professional advice of encouragement to resume light activity alone. They found a short-term improvement immediately after treatment in the group with combined exercise and behavioral training. Vikne et al. [14] compared neck exercise in a ceiling-mounted sling with general exercise. The aim of the neck exercise was to improve neuromuscular function and neck muscle strength and endurance. In both randomization groups, additional pragmatic passive treatment 
modalities were allowed. Both randomization groups were further divided into two groups, those with or without an additional home training program. Some improvements over time, but no group differences were reported [14]. Michaleff et al. [15] reported no advantage of a general exercise program, including neck-specific exercises (NSE) aiming to improve deep neck muscle function, compared to advice alone. Finally Ludvigsson et al. [16, 17] compared three modalities: (1) graded NSE alone, aiming to improve both deep neck muscle function, control and general neck muscle endurance, (2) NSE combined with a behavioral program, and (3) a prescription of general physical activity. After 3 and 6 months, improvements were reported in the two groups that performed NSE when compared to the group that received only a prescription for physical activity. More understanding of the role of NSE as a treatment for WAD is still needed $[13,16]$ to improve rehabilitation potential in patients with more severe problems (WAD grade 3).

Many countries have prolonged waiting times for persons needing rehabilitation for chronic WAD. A limitation of previous studies is that they did not compare the effects of treatment to no treatment at all. As WAD patients may show changes in condition over time without intervention, comparison of some exercise interventions to no treatment might be useful in guiding rehabilitation protocols. Except for a small study by Humphreys \& Ingens [18], no study has investigated individuals with chronic WAD who either performed exercise or remained at waiting list without any intervention. Humphreys \& Ingens [18] investigated the effect of proprioceptive training with eye-head-neck exercises in a sample of 28 patients with chronic (>3 months) neck pain, where $61 \%$ had previously had a whiplash injury. The results of the NSE protocol used in the RCT by Ludvigsson et al. [16, 17] seem promising, but need to be confirmed compared with a no-intervention control group.

The aim of the present study was to investigate individuals with chronic WAD, grades 2 and 3 , over 3 months of either performing NSE $[16,17]$ or remaining on the waiting list without 
exercising. Outcome measures included pain, self-reported neck-related and overall function, self-efficacy, and health-related quality of life.

\section{Methods}

\section{Design}

This is a prospective, randomized controlled study (ClinicalTrials.gov Identifier: NCT01547624) of participants with chronic WAD. Patients were randomized into two groups: A) assigned NSE for 3 months or B) continued on the waiting list with no intervention (WL) for 3 months (Figure 1). Patients who had sought care for WAD in the preceding 3 years were asked to notify the researchers of their interest in participating in the study. Individuals that fulfilled the study criteria participated (60 out of 61) after providing written and informed consent (Figure 1). Questionnaires were conducted before randomization and at the 3-month follow-up. The investigators of the study were blinded to the group designation until the follow-up was complete. Because of the nature of the study, participants and treating physiotherapists could not be blinded to group allocation.

\section{Procedure}

The patients were consecutively randomized using a computerized list to either NSE or WL. The randomization procedure was managed by a researcher that was otherwise not involved 
in the study. Randomization continued for one year (March 2011 to February 2012). For participants randomized to the NSE group, the independent researcher placed the name, address, and telephone number of the participant in a sealed, opaque envelope for distribution to the treating physiotherapist. NSE group participants conducted the exercises at a physiotherapy clinic in primary care/ private practice located near the participant's home.

\section{Participants}

For inclusion into the study, individuals had to be age 18-63 years with chronic symptoms (6 to 36 months) following a whiplash injury classified as WAD grade 2 or $3[5,16]$ with a history of at least one WAD-related health care visit. They also had to record a Neck Disability Index (NDI) score [19] >20/100\%, and/or record an average pain intensity on a Visual Analogue Scale (VAS) of >20/100 mm [20] for the preceding week. (Table 1).

Participants were excluded from the study when they had a more dominant pain elsewhere in the body or reported unconsciousness in connection to the whiplash injury. They were also excluded if they had a health history that contraindicated exercise or could be potentially detrimental to completing the study intervention, or had insufficient competence in Swedish (Table 1).

The participants in the study included 60 individuals (42 women and 18 men) with a mean age of 37 (SD 10.7, range 18-62) years. The mean time since the whiplash accident was 22 $(\mathrm{SD}=11.0)$ months. Injuries were classified as WAD grade $2(\mathrm{n}=39,65 \%)$ or $3(\mathrm{n}=21,35 \%)$ $[5,16])$. Then, patients were consecutively randomized to either the NSE group $(n=31)$ or the WL group ( $\mathrm{n}=29)$ for 3 months. The groups at baseline showed no significant difference ( $p=0.41$ to 0.78 ) for age, gender distribution, WAD level, or duration of WAD (Table 2). A total of 19 individuals dropped out of the study, leaving 41 individuals for final analysis (31 
women and 10 men; mean age of 38 (SD=11.2, range 18-62) years) (Figure 1). Except for a higher baseline neck pain intensity $(\mathrm{p}=0.04)$ among the drop-outs compared to those completing the 3 month program, there were no differences between groups.

\section{Ethics statement}

This study was approved by the Regional Ethics Review Board, Linköping, Sweden, Dnr 2010/188-31.

\section{Intervention}

The physiotherapists, were provided with standardized information about the intervention. The information was provided orally, in writing, and in a practical, one half day class, conducted by the project leaders. The project leaders were available to answer questions from the physiotherapists during the entire period of study.

At the first visit with the treating physiotherapist, NSE participants were once again examined, and they received instruction with a musculoskeletal model to explain their symptoms, the aimed effect of NSE, motivate and encourage them to exercise. The NSE group performed supervised NSE twice a week at the physiotherapy clinic. Initially, the focus was on activity of the deep neck muscles and motor control training, with guidance from the physiotherapist [16, 17] (Appendix 1). Gradually, head resistance exercises were introduced in the gym using pulley weights or a guild board [16, 17, 21, 22] (Appendix 1); these exercises focused on neck muscle endurance. Exercises were performed with low individualized loads, which were gradually increased when tolerated (Appendix 1). For photos and detailed description please see the Academic Archive Online: http://dx.doi.org/10.3384/report.diva-113865). Aggravation of pain was avoided [16, 
17, 23, 24]. To perform the exercises, the participant had to focus on proper position and posture of the neck and torso. Participants also received instruction regarding continuation of NSE with a resistive exercise band to be performed at home following completion of the intervention period.

Participants in the WL received no intervention for 3 months during the study. However, after the study period, they could receive physiotherapy that included NSE, but they were not followed for the present study.

\section{Outcomes}

\section{Neck-specific disability}

Neck-specific disability was measured with the Neck Disability Index (NDI) [19]. The NDI has shown good reliability and validity in WAD studies [25]. NDI scores for neck disability can range from $0 \%$ (no limitation on activity) to $100 \%$ (worst possible disability) [19].

\section{Neck pain}

Neck pain intensity (current pain) was measured with a $100 \mathrm{~mm}$ Visual Analog Scale (VAS). Scores can range from 0 (no pain) to 100 (worst imaginable pain). The VAS have shown good reliability and validity in WAD patients and patients with neck pain [20].

\section{Self-efficacy}

The participants' confidence in their ability to perform activities despite pain was evaluated with the Self-Efficacy Scale (SES) [26, 27]. The SES is comprised of 20 different physical and psychosocial activity items. Scores can range from 0 (not confident at all) to 10 (very confident). Each score was summarized to a total score that ranged from 0-200. The SES is considered a reliable instrument for evaluating WAD populations [28, 29]. 


\section{General pain-related disability}

The Pain Disability Index (PDI) [30] measures the impact that pain has on the ability of a person to participate in essential life activities and has been shown to be reliably measure. Activities are scored on a numeric scale that ranged from 0 (no disability) to 10 (worst disability). The maximum score is 70 .

\section{Health-related quality of life}

Health-related quality of life was assessed with the EuroQol five-dimension selfclassification questionnaire (EQ-5D) [31] and has shown to be a reliable measure [32]. The results from each of the 5 dimension are combined and converted to a score (EQ5D), which can range from -0.594 to 1; higher scores indicate better quality of life [31].

\section{Statistical analysis}

Data were analyzed according to an intention to treat design using non-parametric statistics due to small sample size and non-normal data distribution. The Mann-Whitney U-test was used to assess between-group differences, and the Wilcoxon signed rank test was used to assess within-group differences over time. Descriptive data of outcome measures are presented as medians and interquartile range or as the median change in a score over time and interquartile range. P-values $<0.05$ were regarded as significant. Clinical relevant differences between groups were set at effect size 0.40 [33, 34]. Effect size 0.5 was considered as moderate and 0.8 as large [33, 34]. Because of a lack of previous studies, a sample size estimation was not possible in planning the present study. When post hoc power analyses were performed on the final results, however, $80 \%$ power was reached in all variables except for neck pain, where 64 individuals would have been needed and the PDI, where 460 individuals would have been needed. 


\section{Results}

The between-group results demonstrated that the NSE group had improved significantly more than the WL group regarding the NDI $(p=0.009)$, SES $(p<0.001)$ and the EQ5D $(p<0.01)$, but not in neck pain ( $\mathrm{p}=0.14)$ and PDI (0.29) (Table 3). Clinical relevant differences were reached for NDI, neck pain and SES (ES > 0.40), with large effect sizes for NDI (ES 0.88) and SES (ES 1.26).

In measuring the within-group changes over time, all outcome measures significantly improved in the NSE group ( $<<0.0001)$. In the WL group, all outcome measures had significantly worsened over the 3-month period ( $\mathrm{p}=0.002$ to 0.0002 ), except for PDI, which had improved $(\mathrm{p}=0.0002)$.

\section{Discussion}

The present study showed the importance of NSE, with clear trends of measures. The NSE group showed significant improvements in NDI, SES, and EQ-5D compared to the WL 
group, with strong clinical relevant group differences in NDI and SES. The other two outcome measures, neck pain and PDI, showed insignificant differences between groups which may be due to under-power (Table 3). Nonetheless, the NSE group improved in all outcomes over time in contrast to the WL group, which generally worsened (Table 3). The use of analgesics may have affected the results, however; even though there was no difference at baseline $(\mathrm{p}=0.78)$, fewer participants reported taking analgesics in the NSE group at 3 months $(\mathrm{p}<0.05)$.

The population in the present study consisted of individuals with chronic WAD. These patients are often a lower priority group in the health care system, and moreover, at WAD grade 3, represent a more severe group of individuals than is usually included in studies. The positive findings of NSE are of interest for future consideration and further research and above all show the possibility of treating individuals with chronic WAD and more severe WAD grades.

\section{Previous research}

The results are consistent with those from other studies on patients with chronic pain [16, 17, 24, 35]. The results are also consistent with the only available study comparing exercise (4week) and WL in chronic neck pain [18]. The results from the present study demonstrate more between group changes than those reported in individuals with WAD by Vikne et al. [14] and Michaleff et al. [15]. This difference may be due to different inclusion criteria and that they $[14,15]$ compared interventions, which were believed to have some positive impact on the WAD condition; in contrast, the present study compared NSE treatment to no treatment. The results of the present study cannot be interpreted to suggest that NSE is the best exercise in WAD, but it does seem to have advantages over being on a WL. The findings 
strengthen the results by Ludvigsson et al. [16, 17], who reported that NSE was better than general physical activity and that adding a behavioral component to NSE had limited advantages over NSE alone.

Physiotherapists guided the patients through the exercises and informed them of neck muscle function, but they did not address any potential behavioral issues. Due to the individualized doses and progress and the interaction with the physiotherapist, the possibility that behavioral effects were involved in the mechanism of improved outcome can not be excluded. Selfefficacy which is an important factor in the treatment of individuals with WAD [36] improved in the NSE group. Although both physical and psychological impairments may be features of chronic WAD, our results indicated that NSE alone had potential benefits, even in chronic WAD, including grade 3 . In contrast, it is noteworthy that the symptoms tended to worsen in the WL group.

\section{Generalization and limitation of the study}

The results of the present study can be generalized to individuals of working age with chronic WAD, grades 2 and 3.

One limitation of the present study was the short-term outcome. Although the participants did not seek health care for their neck problems during the time period immediately before inclusion into the study, they had demonstrated interest in the study. In our opinion, it may have been unethical to allow these patients to wait for a longer time period before receiving physiotherapy, with the aim of extending the study period. Nevertheless, a long-term followup may have improved the strength of our findings. In addition, we did not investigate the outcome measures in the WL group after leaving the waiting list. Another limitation was that we did not control for the attention from the physiotherapist in the NSE group. Thus, a 
placebo effect could not be excluded; however, the participants had experienced longstanding neck problems, and all had previously been in touch with the health care system for their WAD. No serious adverse event was reported in any patient completing the study in the NSE group.

In the NSE group of those fulfilling the 3-month follow-up, five individuals showed less than $50 \%$ compliance in their physiotherapy visits (recorded by the physiotherapist). Data analyses which excludes those patients did not change the conclusions of the study.

Although this study was partly underpowered and had the other limitations described, a strength of the study is that it is the first prospective randomized investigation of an intervention in chronic WAD compared to being on a WL.

\section{Conclusion}

In conclusion, NSE showed many benefits over WL on individuals with chronic WAD on a waiting list for care. Thus, specific exercise may be an important intervention to help individuals with chronic WAD from worsening. Although the results are promising, they should be interpreted with caution, due to the low sample size and drop-outs. Randomized controlled studies with larger sample sizes are needed to investigate the role of NSE in the treatment of chronic WAD further, and also to compare NSE to other interventions as well as to no intervention.

\section{References}


1. The Whiplash Commission Final Report. Sandviken; 2005, ISBN 91-975655-4-7. [http://www.whiplashkommissionen.se/www.whiplashkommissionen.se/pdf/WK_finalr eport. pdf].

2. Holm LW, Carroll LJ, Cassidy JD, Hogg-Johnson S, Côté P et al. (2008) The burden and determinants of neck pain in whiplash-associated disorders after traffic collisions: results of the bone and joint decade 2000-2010 task force on neck pain and its associated disorders. Spine 33:S52-S59.

3. Carroll L, Holm L, Hogg-Johnson S, Cote P, Cassidy D et al. (2008) Course and prognostic factors for neck pain in whiplash-associated disorders (WAD). Results of the bone and joint decade 2000-2010 task force on neck pain and its associated disorders. Spine 33:583-592.

4. Leth-Petersen S, Rotger GP (2009) Long-term labour-market performance of whiplash claimants. J Health Econ 28:996-1011.

5. Spitzer WO, Skovron ML, Salmi LR, Cassidy JD, Duranceau J et al (1995) Scientific monograph of the Quebec Task Force on Whiplash-Associated Disorders: redefining "whiplash" and its management. Spine 20: S1-73.

6. Elliott J, Pedler A, Kenardy J, Galloway G, Jull G et al. (2011) The temporal development of fatty infiltrates in the neck muscles following whiplash injury: an association with pain and posttraumatic stress. PLoS One 6: e21194.

7. Jull G, Kristjansson E, DallÀlba P (2004) Impairments in the cervical flexors: a comparison of whiplash and insidious onset neck pain patients. Man Ther 9: 89-94.

8. O`Leary S, Falla D, Jull G (2011) The relationship between superficial muscle activity during the cranio-cervical flexion test and clinical features in patients with chronic neck pain. Man Ther 16:452-455. 
9. Peolsson A, Ludvigsson ML, Wibault J, Dedering Å et al.(2014) Function in patients with cervical radiculopathy or chronic whiplash-associated disorders compared with healthy volunteers. J Manipulative Physiol Ther. 37:211-218.

10. Verhagen AP, Scholten-Peeters G, van Wijngaarden, de Bie RA, Bierma-Zeinstra SM (2007) Conservative treatment for whiplash. Cochrane Database Syst Rev 4:4.

11. Teasell RW, McClure JA, Walton D, Pretty J, Salter K et al (2010) A research synthesis of therapeutic interventions for whiplash-associated disorder (WAD): part 4 noninvasive interventions for chronic WAD. Pain Res Manag 15:313-322.

12. Southerst D, Nordin M, Côte P, Shearer HM, Varatharajan S et al. (2014) Is exercise effective for the management of neck pain and associated disorders or whiplashassociated disorders? A systematic review by the Ontario protocol for traffic injury management (OPTIMa) collaboration. Spine J, E-pub ahead of print Feb 3.

13. Stewart MJ, Maher CG, Refshauge KM, Herbert RD, Bogduk N et al. (2007) Randomized controlled trial of exercise for chronic whiplash-associated disorders. Pain 128:59-68.

14. Vikne J, Oedegaard A, Laerum E, Ihlebaek C, Kirkesola G (2007) A randomized study of new sling exercise treatment vs traditional physiotherapy for patients with chronic whiplash-associated disorders with unsettled compensation claims. J Rehab Med 39:252-259.

15. Michaleff ZA, Maher CG, Lin CW, Rebbeck T, Jull G et al (2014). Comprehensive physiotherapy exercise programme or advice for chronic whiplash (PROMISE): a pragmatic randomised controlled trial. Lancet 384:133-141.

16. Ludvigsson ML, Peterson G, O'Leary S, Dedering A, Peolsson A (2015) The Effect of Neck-specific Exercise with, or without a Behavioral Approach, on Pain, Disability, 
and Self-efficacy in Chronic Whiplash-associated Disorders: A Randomized Clinical Trial. Clin J Pain 31:294-303.

17. Landén Ludvigsson M, Peterson G, Dedering Å, Peolsson A (2015). Two year followup of a randomized clinical trial investigating three different exercise interventions for chronic Whiplash Associated Disorders. J Rehabil Med, Accepted

18. Humphreys BK, Ingens PM (2002) The effect of a rehabilitation exercise program on head repositioning accuracy and reported levels of pain in chronic neck pain subjects. $\mathrm{J}$ Whiplash Relat Disord 1:99-112.

19. Vernon H (2008) The Neck Disability Index: state-of-the-art, 1991-2008. J Manipulative Physiol Ther 31:491-502.7.20. Carlsson AM (1983) Assessment of chronic pain. I. Aspects of the reliability and validity of the visual analogue scale. Pain 16:87-101.

21. Holten O, Faugli HP (1993) Medisinsk treningsterapi. Oslo, Universitetsforlaget ISBN 8200410730. In Norwegian.

22. Peolsson A, Peolsson M, Jull G, O’Leary S (2013) Is there a difference in the pattern of muscle activity when performing neck exercises with a guild board versus a pulley? J Rehabil Med 45:900-905.

23. Van Oosterwijck J, Nijs J, Meeus M, Van Loo M, Paul L (2012) Lack of endogenous pain inhibition during exercise in people with chronic whiplash associated disorders: an experimental study. J Pain 13:242-254.

24. Daenen L, Varkey E, Kellman M, Nijs J (2015) Exercise, not to exercise, or how to exercise in patients with chronic pain? Applying science to practice. Clin J Pain 31:108-114. 
25. Macdermid JC, Walton DM, Avery S, Blanchard A, Etruw E et al (2009). Measurement properties of the neck disability index: a systematic review. J Orthop Sports Phys Ther. 39: 400-1.

26. Altmaier EM, Russell DW, Kao CF, Lehmann TR, Weinstein JN (1993) Role of selfefficacy in rehabilitation outcome among chronic low back pain patients. J Counsel Psychol 40: 335-9.

27. Denison E, Åsenlof P, Lindberg P (2004) Self-efficacy, fear avoidance, and pain intensity as predictors of disability in subacute and chronic musculoskeletal pain patients in primary health care. Pain 111:245-52.

28. Bunketorp L, Carlsson J, Kowalski J, Stener-Victorin E (2005) Evaluating the reliability of multi-item scales: a non-parametric approach to the ordered categorical structure of data collected with the Swedish version of the Tampa Scale for Kinesiophobia and the Self-Efficacy Scale. J Rehabil Med. 37:330-334.

29. Söderlund A, Denison E (2006) Classification of patients with whiplash associated disorders (WAD): reliable and valid subgroups based on the Multidimensional Pain Inventory (MPI-S). Eur J Pain. 10:113-119.

30. Tait RC, Chibnall JT, Krause S (1990) The pain disability index: psychometric properties. Pain 40:171-182.

31. Brooks R. EuroQol (1996) The current state of play. Health Policy 37:53-72.

32. Pink J, Petrou S, Williamson E, Williams M, Lamb SE (2014) Properties of patientreported outcome measures in individuals following acute whiplash injury. Health and Quality of Life Outcomes 12:38

33. Cohen J (1988) Statistical power analysis for the behavioral sciences. Hillsdale, New Jersey: Lawrence Erlbaum Associates, Inc., Publishers; pp. 1e17. 
34. Armijo-Olivo S, Warren S, Fuentes J, Magee DJ (2011) Clinical relevance vs. statistical significance: using neck outcomes in patients with temporomandibular disorders as an example. Man Ther 16:563e72.

35. Gross AR, Goldsmith C, Hoving JL, Haines T, Peloso P et al. (2007) Conservative management of mechanical neck disorders: a systematic review. J Rheumatol 34:10831102.

36. Söderlund A (2011) The role of educational and learning approaches in rehabilitation of whiplash-associated disorders in lessening the transition to chronicity. Spine 36:S280-5. 
Effects of neck specific exercises in whiplash

\section{Figure legends}

Figure 1. Flow-chart of the study investigating the effect of neck-specific exercises for chronic whiplash associated disorders. 
Table 1. Inclusion and exclusion criteria for participation in the study

\section{Inclusion criteria}

- Age 18-63 years

- Chronic whiplash injury (6-36 months)

- $\quad$ WAD grade 2 or $3^{1}$

- $\mathrm{NDI} \geq 20 \%$ and/or $20 \mathrm{~mm}$ VAS

\section{Exclusion criteria}

- Signs of traumatic brain injury

- Myelopathy

- Spinal infection or tumor

- Previous neck surgery

- Previous neck trauma with unresolved symptoms

- More dominant pain elsewhere

- Neck pain that caused more than one month's absence from work in the preceding year, before the whiplash injury

- Psychiatric disorders or known drug abuse

- Diseases that contraindicated performing the exercises in the study

- Insufficient knowledge of the Swedish language to answer the questionnaires

- Ongoing treatment elsewhere

WAD: whiplash-associated disorders; NDI: neck disability index; VAS: visual analogue scale ${ }^{1}$ The Quebec Task Force classified WAD into five severity grades (0-4); grade 0 indicates no neck complaints and no physical sign(s), and grade 4 indicates a neck complaint due to neck 
fracture or dislocation. The symptoms were classified as WAD grade 2 when they originated in the neck and were verified through interview and a manual clinical examination conducted by one of the project leaders (an experienced physiotherapist). The symptoms were considered WAD grade 3 when they originated in the neck and were accompanied by neurological symptoms and signs. 
Table 2. Participants with chronic Whiplash Associated Disorders (WAD) grade 2 and 3 at baseline.

\begin{tabular}{llll} 
& \multicolumn{1}{c}{ NSE $^{1}$} & WL $^{2}$ & p-value \\
\hline Age, mean (SD; range) years & $39(11.2 ; 18-62)$ & $38(11.0 ; 20-60)$ & 0.77 \\
Gender, n(\%) women & $17(74)$ & $14(78)$ & 0.78 \\
WAD grade, n(\%) grade 2 & $18(78)$ & $12(67)$ & 0.41 \\
Duration, mean(SD; range) months & $20(8.3 ; 8-36)$ & $24(13.7 ; 6-60)$ & 0.48
\end{tabular}

${ }^{1} \mathrm{NSE}=$ The neck-specific group

${ }^{2} \mathrm{WL}=$ The waiting list group 
Table 3. Comparison between patients with chronic, whiplash-associated disorders $(n=41)$ that either spent 3 months performing neck-specific exercises (NSE) or 3 months with no intervention, while on a waiting list for treatment (WL).

\begin{tabular}{lllll|llllll}
\hline & $\begin{array}{l}\text { NSE } \\
\text { Baseline }\end{array}$ & $\begin{array}{l}\text { NSE } \\
\text { 3months }\end{array}$ & $\begin{array}{l}\text { NSE } \\
\text { Change } \\
\text { score }\end{array}$ & $\begin{array}{l}\text { P NSE } \\
\text { Over } \\
\text { time }\end{array}$ & $\begin{array}{l}\text { WL } \\
\text { Baseline }\end{array}$ & $\begin{array}{l}\text { WL } 3 \\
\text { months }\end{array}$ & $\begin{array}{l}\text { WL } \\
\text { Change } \\
\text { score }\end{array}$ & $\begin{array}{l}\text { P WL } \\
\text { Over } \\
\text { time }\end{array}$ & $\begin{array}{l}\text { P Change } \\
\text { Between } \\
\text { groups }\end{array}$ & $\begin{array}{l}\text { Effect } \\
\text { size } \\
\text { Between } \\
\text { groups }\end{array}$ \\
\hline NDI & $30(12.0)$ & $18(22.5)$ & $-6(16.0)$ & $<0.0001$ & $24(14)$ & $30(12.0)$ & $2(8.0)$ & $0.0002^{w}$ & 0.009 & 0.88 \\
Neck pain & $34(35.0)$ & $20(49.5)$ & $-7(43.2)$ & $<0.0001$ & $37(36.0)$ & $52(48.0)$ & $4.5(31.0)$ & $0.0003^{w}$ & 0.14 & 0.46 \\
PDI & $16(17.5)$ & $8(14.2)$ & $-5(11.2)$ & $<0.0001$ & $20(18.0)$ & $18(11.0)$ & $-5(7.0)$ & 0.0002 & 0.29 & 0.23 \\
SES & $155(26)$ & $180(49)$ & $14(28.5)$ & $<0.0001$ & $170(27)$ & $154(31)$ & $8(21.0)$ & $0.002^{\mathrm{w}}$ & 0.0005 & 1.26 \\
EQ5D & $0.72(0.046)$ & $0.73(0.07)$ & $0.04(0.11)$ & $<0.0001$ & $0.72(0.036)$ & $0.69(0.47)$ & $0.00(0.07)$ & $0.0003^{\mathrm{w}}$ & 0.009 & 0.37 \\
\hline
\end{tabular}

Values represent the median and interquartile range (IQR); the median change in score (IQR); or the p-values; Changes in score over time were evaluated as: (score at baseline) - (score at 3-month follow-up). $P$ over time: significance of the change within a group over time; $P$ change between groups: significance of the difference between groups in the score change over time. NDI: neck disability index; Neck pain: Current neck pain intensity measured on a visual analogue scale; PDI: pain disability index; SES: self-efficacy scale, EQ5D: Euroqol five dimensions; ${ }^{\mathrm{w}}$ Worse. 


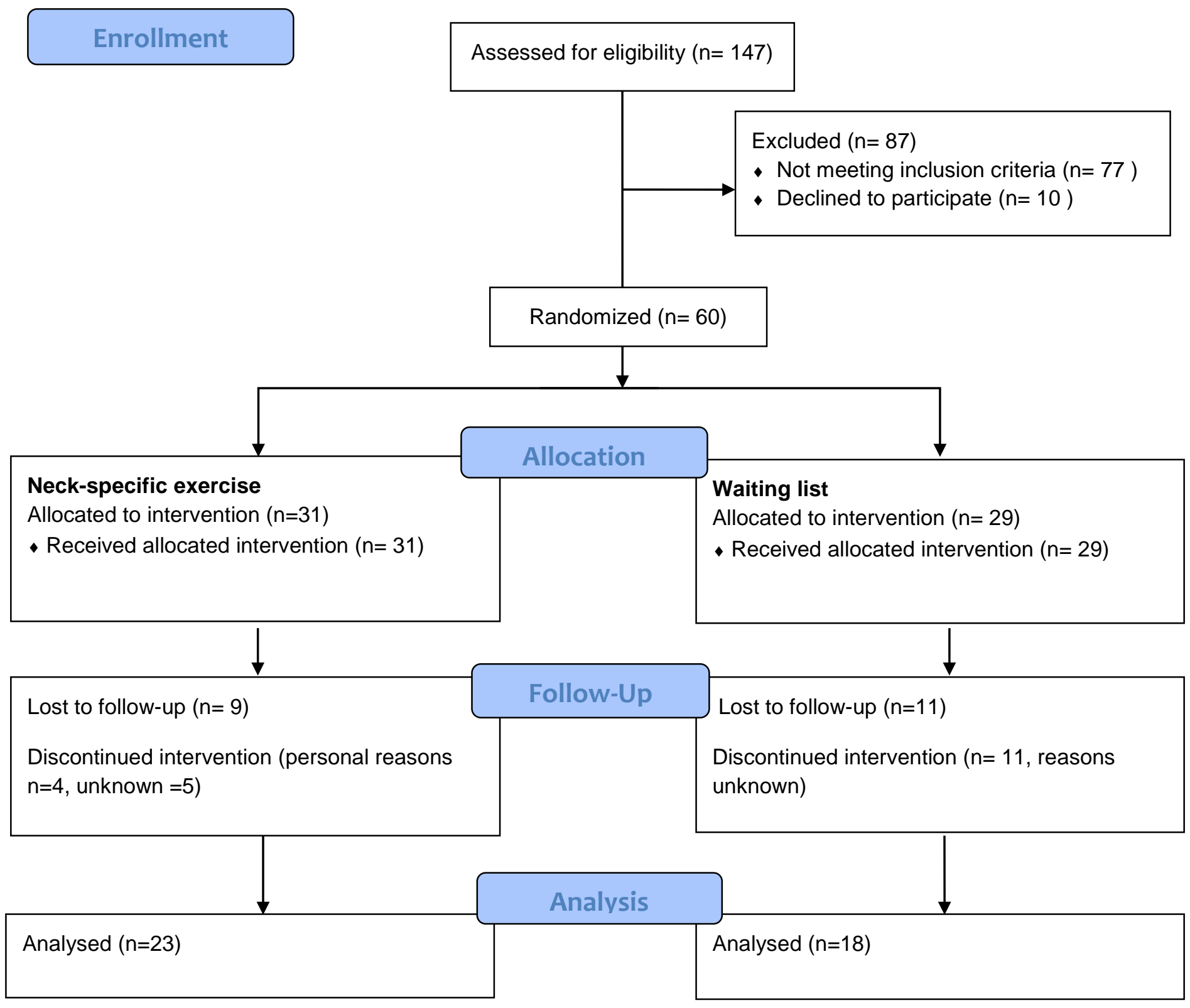

